\title{
Soil microbial community changes in wooded mountain pastures due to simulated effects of cattle grazing
}

\author{
F. Kohler ${ }^{1,2,7,8}$, J. Hamelin ${ }^{3,4}$, F. Gillet ${ }^{1,2,5}$, J.-M. Gobat ${ }^{1,2}$ \& A. Buttler ${ }^{1,5,6}$ \\ ${ }^{1}$ WSL, Swiss Federal Research Institute, Antenne romande, 1015, Lausanne, Switzerland. ${ }^{2}$ Laboratory of \\ Plant Ecology, University of Neuchâtel, 2007, Neuchâtel, Switzerland. ${ }^{3}$ Laboratory of Microbiology, Uni- \\ versity of Neuchâtel, 2007, Neuchâtel, Switzerland. ${ }^{4}$ Laboratoire de Biotechnologie de l'Environnement, \\ Institut National de la Recherche Agronomique (INRA), Avenue des étangs, 11100, Narbonne, France. \\ ${ }^{5}$ Laboratory of Ecological Systems ECOS, Swiss Federal Institute of Technology EPFL, 1015, Lausanne, \\ Switzerland. ${ }^{6}$ Laboratoire de Chrono-écologie, UMR 6565 CNRS, Université de Franche-Comté, 25030, \\ Besançon, France. ${ }^{7}$ Current address: Nature Conservation and Plant Ecology Group, Wageningen University, \\ Bornsesteeg 69, 6708 PD, Wageningen, The Netherlands. ${ }^{8}$ Corresponding author*
}

Received 1 April 2005. Accepted in revised form 15 June 2005

Key words: Biolog Ecoplate ${ }^{\mathrm{TM}}$, dunging, fertilizing, field experiment, herbage removal, trampling

\begin{abstract}
The effect of cattle activity on pastures can be subdivided into three categories of disturbances: herbage removal, dunging and trampling. The objective of this study was to assess separately or in combination the effect of these factors on the potential activities of soil microbial communities and to compare these effects with those of soil properties and plant composition or biomass. Controlled treatments simulating the three factors were applied in a fenced area including a light gradient (sunny and shady situation): (i) repeated mowing; (ii) trampling; (iii) fertilizing with a liquid mixture of dung and urine. In the third year of the experiment, community level physiological profiles (CLPP) (Biolog Ecoplates ${ }^{\mathrm{TM}}$ ) were measured for each plots. Furthermore soil chemical properties ( $\mathrm{pH}$, total organic carbon, total nitrogen and total phosphorus), plant species composition and plant biomass were also assessed. Despite differences in plant communities and soil properties, the metabolic potential of the microbial community in the sunny and in the shady situations were similar. Effects of treatments on microbial communities were more pronounced in the sunny than in the shady situation. In both cases, repeated mowing was the first factor retained for explaining functional variations. In contrast, fertilizing was not a significant factor. The vegetation explained a high proportion of variation of the microbial community descriptors in the sunny situation, while no significant variation appeared under shady condition. The three components of cattle activities influenced differently the soil microbial communities and this depended on the light conditions within the wooded pasture. Cattle activities may also change spatially at a fine scale and short-term and induce changes in the microbial community structure. Thus, the shifting mosaic that has been described for the vegetation of pastures may also apply for below-ground microbial communities.
\end{abstract}

\section{Introduction}

Much research effort has been directed at understanding how agriculture and land use practice

\footnotetext{
* FAX No: + 31 (0)317-484845.

E-mail: florian.kohler@unine.ch
}

influence the structure and diversity of animal and microbial below-ground communities (Chabrerie et al., 2003; Clegg et al., 2003; Grayston et al., 2004; Larkin, 2003). The role of soil organisms in regulating ecosystem processes has received growing attention over the past several years and there 
is an increasing number of studies on questions such as how decomposers respond to disturbance regimes especially those related to agriculture (Guitian and Bardgett, 2000; Wardle et al., 1999; Yeates et al., 1997).

The agricultural activity in mountain regions around the world is mainly based on grazing by large herbivores, principally cattle and sheep. Grazing is the main biotic factor affecting ecosystem structure and dynamics in pastures (Bokdam and Gleichman, 2000; Olff et al., 1999). The effect of cattle or sheep on their environment can be subdivided into three categories of stress factors: herbage removal, dunging and trampling. Many studies have addressed effects of grazing (e.g., Cingolani et al., 2003; Milchunas and Lauenroth, 1993; Schlaepfer et al., 1998), trampling (Cole, 1995; Guethery and Bingham, 1996), dung deposition (Dai, 2000; Malo and Suarez, 1995), manuring or fertilizing (Gough et al., 2000) on grassland, heathland or woodland plant communities. Moreover, herbage removal, manuring and trampling have significantly different effects on seasonal plant dynamics of grasslands (Kohler et al., 2004).

Effects of herbage removal by large herbivores on soil microbial communities are also well recognized (Bardgett and Wardle, 2003; Bardgett et al., 1998). It changes the arrangement of above-ground parts of plants with consequences for above- vs. below-ground carbon allocation and nitrogen-cycling (Holland and Detling, 1990). Defoliation of grass species induces an increase in soil-extractable microbial $\mathrm{C}$ and $\mathrm{C}$ use efficiency in the rhizosphere (Guitian and Bardgett, 2000). Bardgett et al. (2001) showed that microbial biomass of soil estimated by PLFA (phospholipids fatty acids) analysis was maximal at low-to-intermediate levels of sheep grazing. In contrast Tracy and Frank (1998) observed no effect of grazing by large herbivores on microbial biomass but on nitrogen mineralization. Dung and urine deposition and more generally fertilizing or manuring change the local nutrient balance. Like defoliation they accelerate nitrogen cycling by more efficient re-circulation of nutrients through the animal excreta pathway (Ruess and McNaughton, 1987). The addition of synthetic urine to upland grassland resulted in a dramatic and short-term change in the soil microbial community structure and activity as measured by community level physiological profiles (CLPP) (Williams et al., 2000). The effect of trampling by cattle on microbial community is less studied. In tropical forest Martinez and Zinck (2004) showed evidence of soil compaction through cattle trampling after clearing primary forests. Compaction implies an increase in soil bulk density and in soil strength and consequently a decrease in air permeability and hydraulic conductivity (Whalley et al., 1995). As a result, $\mathrm{N}$ mineralization is reduced (Breland and Hansen, 1996). Moreover, compaction also affected microbial activity by reducing acid phosphatase (Jordan et al., 2003).

Each of the cited studies considers only one of the three disturbances or considers herbivores activities as a single factor called 'grazing'. Surprisingly the relative impacts of herbage removal, dung deposition and trampling or their interactions on the activity or the structure of the microbial communities of pastures are not considered. Furthermore, the spatial patterns of the three activities are not congruent. Cattle have, for example, preferred resting and dunging areas, which may be different from their preferred grazing areas (Bokdam and Gleichman, 2000). In addition, the field studies compared existing situations with little control over the fields and independent variables (pseudoexperiment) (e.g., Bardgett et al., 2001; Donnison et al., 2000; Grayston et al., 2004) and microcosms were usually used in experiments (e.g., Bardgett et al., 1999; Jordan et al., 2003). Only a few studies used controlled field experiments (Clegg et al., 2003; Harrison and Bardgett, 2004; Wardle et al., 1999; Williams et al., 2000).

The objective of this study was to assess, separately or in combination in an exclosure field experiment of 3 years duration, the relative effects of repeated mowing, fertilizing and trampling on the structure of microbial communities using Biolog Ecoplates ${ }^{\mathrm{TM}}$ and to compare these effects with effects of soil chemical composition and plant composition or biomass. In order to account for the heterogeneous conditions induced by trees in wooded pastures, two light conditions were also considered.

Our hypotheses were: (1) treatments such as herbage removal, trampling and dunging induce different changes in the microbial community either directly or indirectly through changes in the 
plant species composition or in the vegetation yield, (2) differing light conditions create different micro-climatic conditions and plant species composition and consequently different microbial activities.

\section{Materials and methods}

\section{Study site}

This study was conducted in the Jura Mountains of north-western Switzerland. The study site was La Métairie d'Évilard (Orvin BE, 47 $09^{\prime} \mathrm{N}, 7^{\circ} 10^{\prime}$ W) at an elevation of about $1200 \mathrm{~m}$ a.s.l. The climate is predominantly temperate oceanic, with mean annual rainfall of about $1600 \mathrm{~mm}$ (with more than $400 \mathrm{~mm}$ snow precipitation) and mean annual temperature of $7{ }^{\circ} \mathrm{C}$. The ground is covered with snow from November to April. The area contains a great diversity of habitats, from open grasslands to forest patches, with flat or sloping ground and a heterogeneous soil cover (Leptosols, Cambisols, Luvisols; taxonomy after Deckers et al. (1998)). Climax vegetation is a beech forest. This patterned landscape has resulted from decades of cattle activities and extensive management with a rotational grazing system.

\section{Experimental design}

The experiment was carried out in an exclosure of $1000 \mathrm{~m}^{2}$ on a flat pasture along a forest margin, which created a lateral shade gradient (Figure 1). Two lines with 24 plots $(1.8 \times 1.8 \mathrm{~m})$ each were established: (i) one in the shady part, with about $3 \mathrm{~h}$ of sun per day from May to October, and (ii) one in the sunny part, with $10 \mathrm{~h}$ of sun per day. Plots were grouped in three blocks of eight plots placed side by side. A pathway of $1 \mathrm{~m}$ separated each block. The shade conditions also induced a colder environment near the trees and a distinct plant species assemblage. These effects are confounded and described by the term "shade effect". In the sunny part the initial plant community was a homogeneous, mesotrophic, unfertilized, extensively grazed Cynosurion meadow. Dominant species of this community were Festuca nigrescens Lam., Agrostis capillaris L., Luzula campestris (L.) DC., Trifolium pratense L. and Alchemilla monticola Opiz (Nomenclature follows:

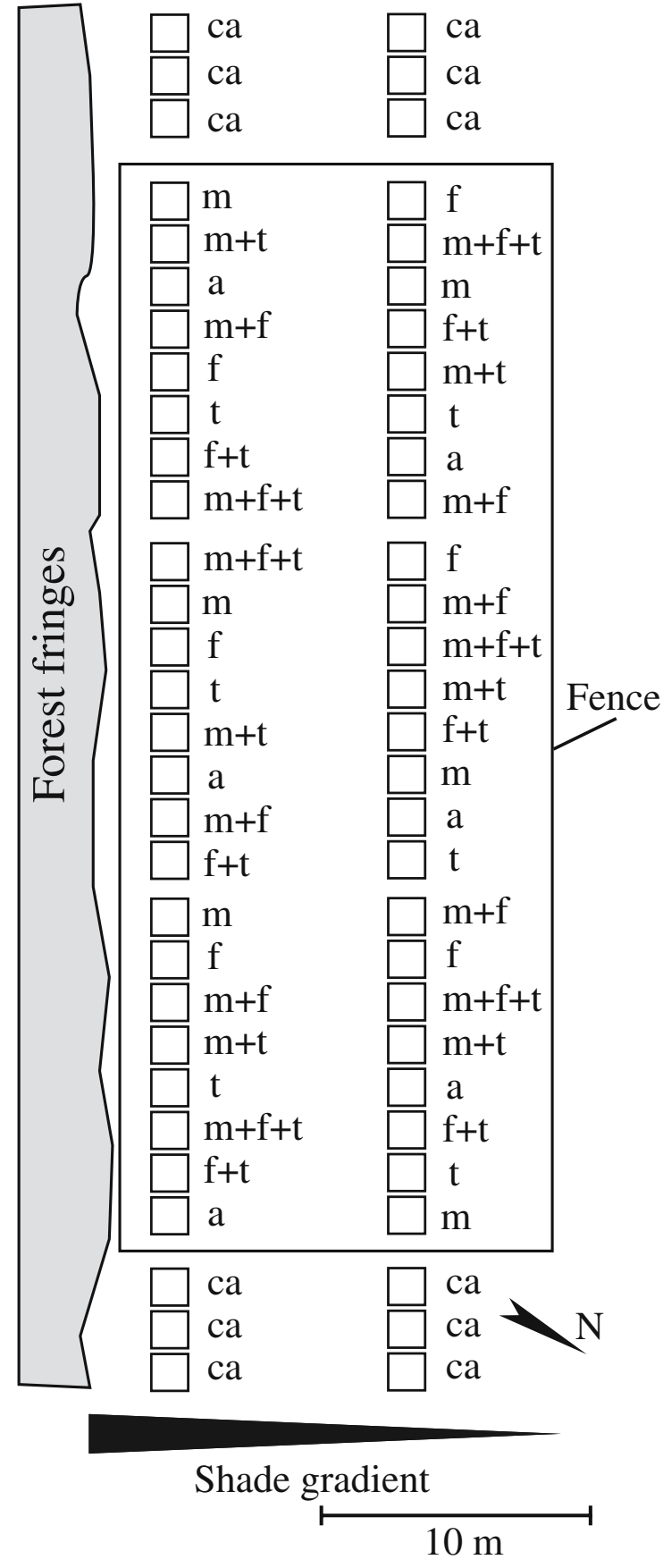

Figure 1. Experimental design with three blocks of plots in two shade conditions in the exclosure and additional plots under the influence of cattle activity. f: fertilizing, m: repeated mowing, $\mathrm{t}$ : trampling, a: abandoned, ca: normal cattle activity.

Tutin et al. (1964-1980)). In the shady part, the initial community was a forest-edge community dominated by Luzula sylvatica (Huds.) Gaudin, 
Geranium sylvaticum L., Festuca nigrescens Lam., Anemone nemorosa L., and Narcissus pseudonarcissus L.

In the exclosure, controlled treatments were applied to simulate herbage removal, trampling and dunging by cattle. The experimental area was fenced in 2001 to prevent large herbivores (heifers and roe deers) from interfering with the treatments. Activities of small herbivores were not controlled but there were no ground holes in the vicinity and rabbits were absent from the region (F. Kohler, personal observation). In the pasture around the exclosure, 12 additional plots were established, 6 in the shady and 6 in the sunny part. At the beginning of the experiment, the 30 plots of each line were as similar as possible with respect to floristic composition, canopy structure and biomass (see Kohler et al. (2004) for a more detailed description of floristic composition at the start of the experiment). The soil was a homogeneous cambisol in the whole area. Three factors were introduced individually and in combination in the exclosure: (1) repeated mowing (m) with a lawn mower twice a month with a cutting height at $30 \mathrm{~mm}$ and removal of the cut biomass, (2) trampling (t) with wooden shoes (1000 footsteps per $\mathrm{m}^{2}$ with ca. $70 \mathrm{~kg}$ per footstep of $0.0035 \mathrm{~m}^{2}$, representing a mean pressure of $20,000 \mathrm{~kg} \mathrm{~m}^{-2}$ ) once a month and (3) fertilizing (f) with a liquid mixture of dung and urine given once a month $\left(2 \mathrm{~L} \mathrm{~m}^{-2}\right)$. The frequency and the height of the cutting allowed maintaining a vegetation height below $0.1 \mathrm{~m}$. For trampling, the pressure was equivalent to that of a heifer (about $400 \mathrm{~kg}$ on at least two hoofs of about $0.01 \mathrm{~m}^{2}$ each). Moreover, the quantity of liquid mixture was equivalent to an intensive cattle activity (Ryser et al., 2001). The liquid mixture came from cattle living in the study area. A balanced factorial design with three replicates was established in both communities giving eight different treatments: three single treatments: $\mathrm{m}, \mathrm{f}, \mathrm{t}$; three coupled treatments: $\mathrm{m}+\mathrm{f}, \mathrm{m}+\mathrm{t}, \mathrm{f}+\mathrm{t}$; one triple treatment: $\mathrm{m}+\mathrm{f}+\mathrm{t}$ and one treatment without disturbance. The last treatment will be referred to as "abandoned" (a). The treatments were allocated randomly to plots within each of three blocks in each line (Figure 1). All treatments were applied homogeneously to the entire surface of each plot, from the end of May to the end of September in 2001 and again in 2002.
This period corresponded to the presence of cattle on the pastureland. Apart from this period, the vegetation was not artificially disturbed and snow covered the soil from November to April. The 12 plots outside the fenced area were defined as reference plots with regular, uncontrolled, cattle activity (ca).

\section{Vegetation data}

Records were made in $1-\mathrm{m}^{2}$ central subplots, leaving a buffer strip of $0.4 \mathrm{~m}$. Absolute and relative cover of vascular plants was assessed using pointintercept frequency measurements (Daget and Poissonet, 1969). The number of contacts of green parts with a vertical needle was counted, considering only the first hit for each species. A threshold of 120 points per subplot was retained since it allowed efficient measurements, with a fair estimation of cover. Since rare species are often missed by this method (Buttler, 1992), a complete list of all species observed within each subplot was also recorded. Consequently, in the data set, species found with no contact were given the minimum value 1 for their occurrence. The records were made at the beginning of June 2003.

Furthermore above-ground biomass was measured at maximum biomass in the middle of June 2003. The $1-\mathrm{m}^{2}$ central subplot was cut and the plant material was sorted in three taxonomic groups: forbs, legumes and grasses. The dry weight of each fraction was determined after $48 \mathrm{~h}$ at $60{ }^{\circ} \mathrm{C}$.

\section{Soil sampling and analysis}

To measure the effect of treatments after two complete years of experiment (June 2001-June 2003), 2 soil cores were extracted at the beginning of June 2003 in each of the 60 plots. Because temporal variation in microbial communities is pronounced at seasonal scale (Griffiths et al., 2003) all cores were taken the same day. The cores had a diameter of $60 \mathrm{~mm}$ and a length of $100 \mathrm{~mm}$, corresponding to the thickness of the A horizon of the cambisol. To eliminate the litter we discarded the two uppermost centimeters. Both cores from each plot were pooled to give one soil sample per plot, which was then homogenized, sieved $(<2 \mathrm{~mm})$ and further analyzed. For each soil 
sample, four variables were measured with standard methods (Anderson and Ingram, 1993). On dry ground soil we analyzed total organic carbon (Ctot), total nitrogen (Ntot), total phosphorus (Ptot) and water $\mathrm{pH}$.

\section{Ecoplates $^{\mathrm{TM}}$ inoculation and incubation}

The number of viable bacteria in the inocula was first determined as colony forming units (CFU) on 10-fold diluted Tryptone Soy Agar $\left(3 \mathrm{~g}^{-1}\right)$ after incubation at $24{ }^{\circ} \mathrm{C}$ for $48 \mathrm{~h}$. Then, $1 \mathrm{~g}$ of each fresh soil sample was diluted in sterile phosphate buffer $10 \mathrm{mM}$ pH $7\left(\mathrm{Na}_{2} \mathrm{HPO}_{4} / \mathrm{NaH}_{2} \mathrm{PO}_{4}\right)$ to obtain about $10^{3} \mathrm{CFU}$ per $\mathrm{ml}$, according to Zak et al. (1994). One Biolog Ecoplate ${ }^{\text {TM }}$ (Biolog Inc., Hayward, CA, USA) was inoculated per sample with $150 \mu \mathrm{l}$ of suspension per well. One plate contains a triplicate of each substrate type allowing three measurements for each sample. The negative control corresponded to a well without any carbon source. The 31 substrates used are listed in Table 1, and were classified into the following biochemical categories (according to Insam (1997)): Polymers (Po), carbohydrates $(\mathrm{CH})$, carboxylic acids $(\mathrm{CA})$, amino acids (AA), amines/amides (Am). Incubation of the Ecoplates ${ }^{\mathrm{TM}}$ was carried out in the dark at

Table 1. Mean ( \pm standard error) of corrected Abs. (see in text) for the 31 substrates in shady and sunny situations $(n=30)$. Substrates were ordered in the descending order of their value in the sunny situation

\begin{tabular}{lll}
\hline Substrates & Shady & Sunny \\
\hline D-Mannitol (CH) & $1.31 \pm 0.24$ & $2.83 \pm 0.45$ \\
Pyruvic acid methyl ester (CA) & $2.56 \pm 0.38$ & $2.41 \pm 0.36$ \\
N-Acetyl-D-Glucosamine (CH) & $2.04 \pm 0.39$ & $2.22 \pm 0.24$ \\
D-Galacturonic acid (CA) & $1.41 \pm 0.47$ & $2.17 \pm 0.51$ \\
Tween 40 (Po) & $3.24 \pm 0.35$ & $2.11 \pm 0.24$ \\
L-Asparagine (AA) & $0.97 \pm 0.20$ & $1.64 \pm 0.30$ \\
Tween 80 (Po) & $1.57 \pm 0.24$ & $1.58 \pm 0.19$ \\
D-Galacturonic acid $\gamma$-Lactone (CA) & $1.12 \pm 0.39$ & $1.40 \pm 0.33$ \\
L-Phenylalanine (AA) & $0.97 \pm 0.19$ & $1.35 \pm 0.22$ \\
D-Glucosaminic acid (CA) & $2.25 \pm 0.49$ & $1.34 \pm 0.49$ \\
L-Arginine (AA) & $1.02 \pm 0.23$ & $1.31 \pm 0.26$ \\
D-Cellobiose (CH) & $0.89 \pm 0.19$ & $0.96 \pm 0.20$ \\
D-Xylose (CH) & $1.28 \pm 0.27$ & $0.92 \pm 0.21$ \\
D-Malic acid (CA) & $1.80 \pm 0.67$ & $0.90 \pm 0.21$ \\
$\alpha$-Ketobutyric acid (CA) & $0.99 \pm 0.13$ & $0.89 \pm 0.18$ \\
4-Hydroxy benzoic acid (CA) & $0.82 \pm 0.18$ & $0.84 \pm 0.17$ \\
$\gamma$-Hydroxybutyric acid (CA) & $0.93 \pm 0.15$ & $0.75 \pm 0.14$ \\
L-Threonine (AA) & $0.58 \pm 0.11$ & $0.61 \pm 0.10$ \\
Glycogen (Po) & $0.55 \pm 0.11$ & $0.51 \pm 0.10$ \\
Itaconic acid (CA) & $0.61 \pm 0.20$ & $0.47 \pm 0.11$ \\
$\alpha$-Cyclodextrine (Po) & $0.53 \pm 0.11$ & $0.43 \pm 0.09$ \\
Glucose-1-phosphate (CH) & $0.18 \pm 0.04$ & $0.43 \pm 0.11$ \\
Glycyl-L-glutamic acid (AA) & $0.45 \pm 0.09$ & $0.43 \pm 0.08$ \\
$\beta$-Methyl-D-Glucoside (CH) & $0.36 \pm 0.15$ & $0.39 \pm 0.09$ \\
L-Serine (AA) & $0.50 \pm 0.10$ & $0.36 \pm 0.05$ \\
i-Erythritol (CH) & $0.36 \pm 0.07$ & $0.35 \pm 0.07$ \\
Phenylethyl-amine (Am) & $0.82 \pm 0.24$ & $0.35 \pm 0.06$ \\
$\alpha$-D-lactose (CH) & $0.25 \pm 0.05$ & $0.33 \pm 0.10$ \\
Putrescine (Am) & $0.24 \pm 0.07$ & $0.33 \pm 0.09$ \\
2-Hydroxy benzoic acid (CA) & $0.28 \pm 0.06$ & $0.31 \pm 0.05$ \\
D,L- $\alpha$-Glycerol phosphate (CH) & $0.10 \pm 0.03$ & $0.09 \pm 0.02$ \\
\hline Bichenicalcat & $\mathrm{CA}$ & \\
\hline & &
\end{tabular}

Biochemical categories: Po: polymers, $\mathrm{CH}$ : carbohydrates, CA: carboxylic acids, AA: amino acids, Am: amines/amides. 
$24{ }^{\circ} \mathrm{C}$ for $120 \mathrm{~h}$ without agitation, and the level of respiratory activity for each well was determined at the end of incubation by measuring the optical densities at $630 \mathrm{~nm}\left(\mathrm{OD}_{630}\right)$ using an automatic microplate reader (Dynatech MR7000).

\section{Statistical analysis}

For each Ecoplate ${ }^{\mathrm{TM}}$, the absorbance value of the control well was subtracted from the well absorption, yielding a single corrected value, according to the manufacturer's instructions. Occasional negative values were set to zero. The average well color development (AWCD) among the three replicates of the 31 substrates was then calculated (Garland and Mills, 1991). The value of each individual well was then divided by the AWCD to compensate for variation in well color development caused by different cell densities of the inocula (Garland, 1996). Finally, for each substrate we calculated the average value from the three replicates of each plate. This calculated variable is referred to as "corrected Abs." in the following. We calculated a value for each biochemical category (carboxylic acids, polymers, carbohydrates, amino acids and amine/amide) by summing the average values of all substrates within a category (see Table 2).

We compared the sunny and the shady situation by calculating the mean and standard error of soil, vegetation and microbial variables (Table 2). To analyze the multivariate variation of each data set, non-metric multidimensional scaling (NMDS) was used. For soil pH, Ntot, Ctot, Ptot and the two ratios $\mathrm{C} / \mathrm{N}$ and $\mathrm{N} / \mathrm{P}$ were used with the Euclidean distance on standardized data. For microbial data we used the Ecoplate ${ }^{\mathrm{TM}}$ matrix (including corrected Abs. of the 31 substrates) with the Bray-Curtis distance (Legendre and Legendre, 1998) and for vegetation data we used the point-intercept species records again with the Bray-Curtis distance. Furthermore redundancy analysis (RDA) was used to evaluate and test the amount of variation in each data set explained by the light conditions (binary variable). Calculations were done with R 1.9.0 (R Development Core Team, 2004).

For each light condition separately, partial RDA was used for partitioning the influence of soil, vegetation and treatments on the microbial

Table 2. Mean ( \pm standard error) of soil, vegetation and microbial community characteristics in the shady $(n=30)$ and sunny $(n=30)$ situation

\begin{tabular}{lrr}
\hline & \multicolumn{1}{c}{ Shady } & Sunny \\
\hline Microbial community & & \\
Number of CFU $\left(10^{7} \mathrm{~g}^{-1}\right)$ & $6.19 \pm 0.90$ & $6.03 \pm 0.54$ \\
AWCD 5 days & $0.11 \pm 0.01$ & $0.17 \pm 0.02$ \\
Polymers (Po) (sum of corrected Abs.) & $5.89 \pm 0.45$ & $4.62 \pm 0.33$ \\
Carbohydrates (CH) (sum of corrected Abs.) & $6.78 \pm 0.60$ & $8.53 \pm 0.51$ \\
Carboxylic acids (CA) (sum corrected Abs.) & $12.78 \pm 0.88$ & $11.48 \pm 0.62$ \\
Amino acids (AA) (sum of corrected Abs.) & $4.49 \pm 0.40$ & $5.68 \pm 0.35$ \\
Amines/amides (Am) (sum of corrected Abs.) & $1.05 \pm 0.25$ & $0.68 \pm 0.10$ \\
Soil & & \\
pH $\mathrm{H}_{2} \mathrm{O}$ & $4.85 \pm 0.04$ & $5.12 \pm 0.03$ \\
Ctot (\%) & $5.72 \pm 0.19$ & $5.57 \pm 0.10$ \\
Ntot (\%) & $0.50 \pm 0.02$ & $0.56 \pm 0.01$ \\
Ptot (\%) & $0.13 \pm 0.01$ & $0.17 \pm 0.01$ \\
C:N & $11.38 \pm 0.15$ & $10.01 \pm 0.09$ \\
N:P & $3.83 \pm 0.13$ & $3.37 \pm 0.10$ \\
Vegetation & & \\
Biomass (g DM m ${ }^{-2}$ ) & $98.6 \pm 7.4$ & $221.5 \pm 16.5$ \\
Percentage of grasses & $72.8 \pm 2.9$ & $47.0 \pm 2.3$ \\
Percentage of legumes & $0.4 \pm 0.1$ & $10.4 \pm 1.3$ \\
Percentage of forbs & $26.8 \pm 2.9$ & $42.6 \pm 2.4$ \\
Species richness (species ${ }^{-2}$ ) & $27.0 \pm 0.7$ & $29.5 \pm 0.7$ \\
\hline
\end{tabular}


community. For this analysis, we used three sets of explanatory variables: (1) soil ( $\mathrm{pH}, \mathrm{Ntot}$, Ctot, Ptot, $\mathrm{C} / \mathrm{N}$ and $\mathrm{N} / \mathrm{P}$ ), (2) vegetation (total plant biomass, percentage of grass, legumes and forbs) and (3) treatments (fertilizing, mowing and trampling and their interactions coded as binary variables). In this analysis blocks were used as covariables. Plots with natural cattle activity were not taken into account because they were not included in the experimental design. The partial RDA permitted the extraction of the variation in the Ecoplates ${ }^{\mathrm{TM}}$ dataset explained by each of the three sets of explanatory variables and shared by these three data sets (see Borcard et al. (1992) and Økland and Eilertsen (1994) for details and Kaufmann et al. (2004) for an example with Biolog ${ }^{\mathrm{TM}}$ data). The whole process was based on computations made with CANOCO 4.5 (ter Braak and Smilauer, 2002). To avoid overfitting in the regression model due to the large number of explanatory variables, we performed forward selection (CANOCO option) retaining for each set the best significant model with the most variables.

A three-way analysis of variance (fertilizing $\times$ mowing $\times$ trampling) was carried out on the five biochemical substrate categories, on AWCD, and on the number of culturable bacteria in order to determine statistically differences between the experimental factors. Overall differences among blocks were included in all ANOVA models and data from plots with natural cattle activity were excluded for the same reason as mentioned above. Calculations were done with R 1.9.0 (R Development Core Team, 2004).

\section{Results}

\section{Differences shady vs. sunny}

For the mean of corrected Abs. in both locations (Table 1), there was a high positive correlation between corrected Abs. of both communities (Spearman rank correlation $=0.90, \quad P<0.001$ ) indicating similar high-used-substrates and low-used-substrates in both locations. In the shady situation the five most used substrates were one polymer, three carboxylic acids and one carbohydrate and in the sunny situation one polymer, two carboxylic acids and two carbohydrates. Furthermore standard errors were in most cases high, indicating high variation between plots. For the other microbial community variables (Table 2), there were again only small differences and high standard errors. Only AWCD was clearly higher for plots in the sunny situation. For the soil variables, mean values were also similar. In the sunny situation $\mathrm{pH}$ and Ptot were higher and $\mathrm{C} / \mathrm{N}$ and N/P lower. Standard errors were low indicating few variations in both situations. For vegetation, biomass was more than two times higher in the sunny situation. Moreover, grasses were dominant in shady plots whereas legumes and forbs were more frequent in the sunny plots. These results were confirmed by NMDS. On the scatter plot, points overlapped for microbial activities, indicating no clear difference between shade and sun (Figure 2a), whereas a clear difference appeared for vegetation records (Figure 2b) and a less clear difference for soil (Figure 2c). For microbial communities the shady plots were more
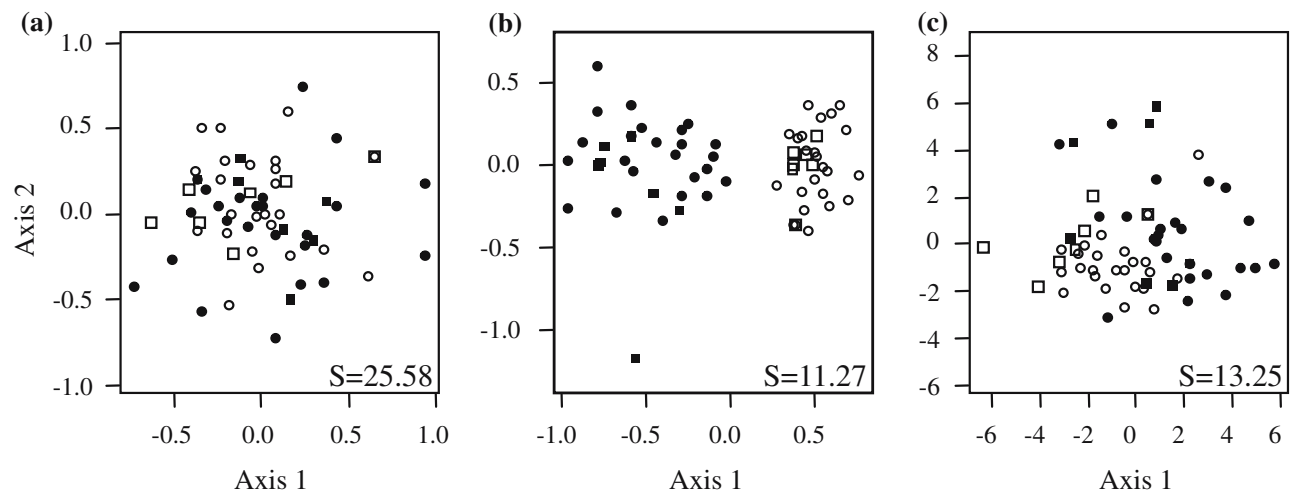

Figure 2. Non-metric multidimensional scaling for Biolog Ecoplate ${ }^{\mathrm{TM}}$ data (a), vegetation records (b) and soil samples (c). Black: shady; white: sunny; circle: plot in the experimental design; square: plot with natural cattle activity. S: Stress. 
Table 3. Summary of RDAs on Ecoplates ${ }^{\mathrm{TM}}$, soil or vegetation datasets constrained by light conditions (binary variable)

\begin{tabular}{lll}
\hline Data set & Explained variance & $P$-value \\
\hline Microbial & $3.3 \%$ & 0.020 \\
Soil & $24.9 \%$ & 0.001 \\
Vegetation & $43.7 \%$ & 0.001 \\
\hline
\end{tabular}

Block effects were removed from all analysis and vegetation data transformed with the Hellinger transformation (Legendre and Gallagher 2001). Monte Carlo permutation test was performed by permuting samples freely within each block (999 permutations).

dispersed indicating more variation between them. For each data set, plots with natural cattle activity were near those of the experimental design within each of the light conditions, excepted one in the vegetation record (this plot appeared to be a cattle pathway during the study). This indicates that treatments were representative of the natural conditions. Results of separate RDAs on the three datasets confirmed results of NMDSs (Table 3) with a high variation explained by light conditions for the vegetation, less for soil properties and only few for microbial activities.

Contribution of treatments, soil and vegetation in microbial variation

For explaining the variation in the Ecoplates ${ }^{\mathrm{TM}}$ dataset in the sunny situation all variables of the vegetation data set were selected (rank of explained variance: $\%$ legumes $>\%$ grasses $>\%$ forbs $>$ biomass). They explained together $32.9 \%$ of the variation (Monte Carlo permutation test with 999 permutations: $P=0.005$ ). For the treatments the four selected variables were, in the rank of the forward selection: $\mathrm{m}>\mathrm{m} \times \mathrm{t}>\mathrm{t} \times$ $\mathrm{f}>\mathrm{t}$. This submodel explained $24.5 \%$ of the variation $(P=0.02)$. For soil variables no significant model was found and consequently soil data were omitted from this analysis. Together the eight selected variables gave a significant model $(P=0.003)$, which explained $55.0 \%$ of the variation (Figure 3). The variation of each set without the effect of the second was also significant (Figure 3). For each set, percentages of variation presented in Figure 3 are those without the shared variation. The shared variation is a consequence of similar structure in the two sets.

For the shady situation (Figure 3), results were less clear. For the vegetation subset no model was significant and this data set was therefore not integrated in the model. For treatments two variables were retained: $\mathrm{m}>\mathrm{m} \times \mathrm{f}$. This submodel explained $13.6 \%$ of the variation in the Ecoplates ${ }^{\mathrm{TM}}$ dataset and it was significant $(P=0.04)$. For soil variables only $\mathrm{pH}$ was retained. This variable explained $9 \%$ of the variation $(P=0.05)$. The full model explained $24.2 \%$ of the variation $(P=0.02)$. The variation of each
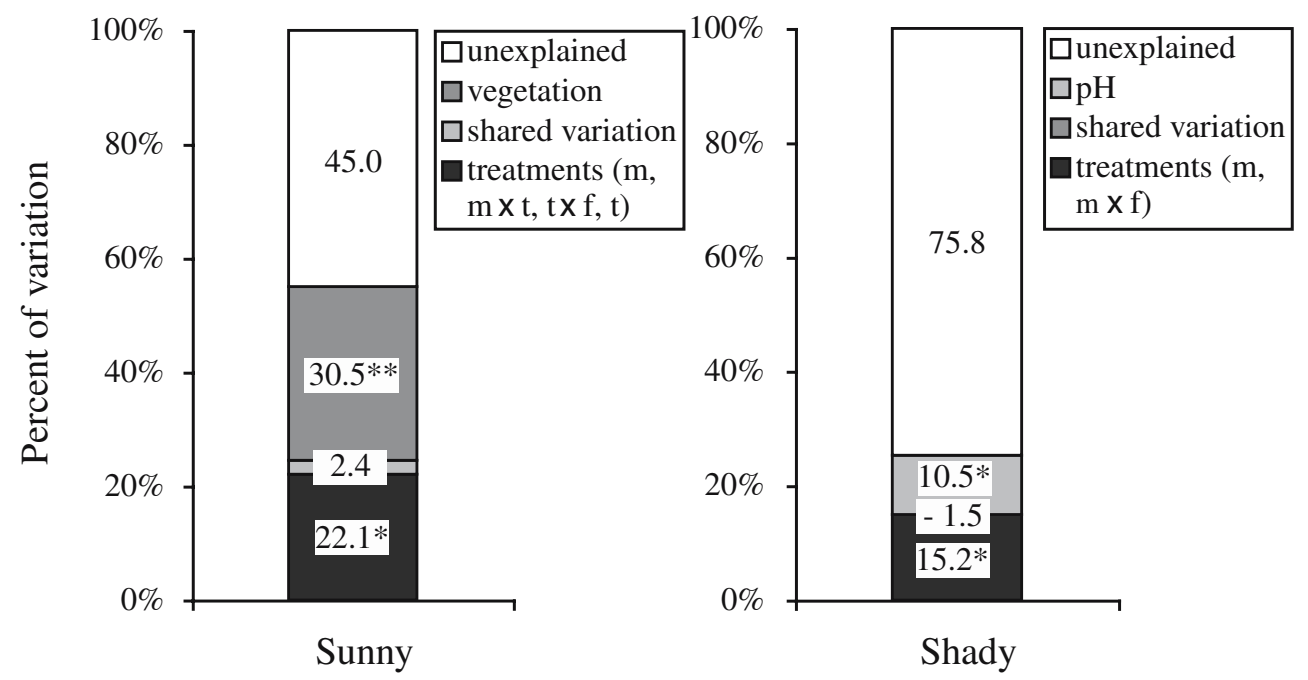

Figure 3. Variation partitioning with partial RDA of Biolog Ecoplate ${ }^{\mathrm{TM}}$ data according to treatments, vegetation and soil data (only significant variables). Monte Carlo permutation test was performed on each set without the effect of the other by permuting samples freely within each block (999 permutations). ( ${ }^{*} P<0.05 ; * * P<0.01$ ). 
Table 4. Significant effects of treatments on biochemical categories of substrates (three-way ANOVA $\mathrm{m} \times \mathrm{f} \times \mathrm{t}$ )

\begin{tabular}{|c|c|c|c|c|c|c|c|c|c|}
\hline & \multirow[t]{3}{*}{$\mathrm{df}$} & \multicolumn{6}{|c|}{ Sunny } & \multirow{2}{*}{\multicolumn{2}{|c|}{$\frac{\text { Shady }}{\text { Amino acids (AA) }}$}} \\
\hline & & \multicolumn{2}{|c|}{$\begin{array}{l}\text { Carboxylic } \\
\text { acids (CA) }\end{array}$} & \multicolumn{2}{|c|}{ Polymers (Po) } & \multicolumn{2}{|c|}{$\begin{array}{l}\text { Carbo-hydrates } \\
(\mathrm{CH})\end{array}$} & & \\
\hline & & $F$ & $P$ & $F$ & $P$ & $F$ & $P$ & $F$ & $P$ \\
\hline block & 2 & 2.04 & $\mathrm{~ns}$ & 0.66 & ns & 1.69 & $\mathrm{~ns}$ & 2.52 & ns \\
\hline $\mathrm{m}$ & 1 & 6.36 & $*$ & 1.61 & ns & 2.41 & ns & 8.01 & $*$ \\
\hline$f$ & 1 & 0.44 & ns & 1.83 & ns & 1.09 & ns & 0.22 & ns \\
\hline $\mathrm{t}$ & 1 & 0.01 & ns & 4.64 & $*$ & 2.89 & $\mathrm{~ns}$ & 0.19 & ns \\
\hline $\mathrm{m} \times \mathrm{f}$ & 1 & 0.27 & ns & 0.38 & ns & 0.13 & ns & 0.07 & ns \\
\hline $\mathrm{m} \times \mathrm{t}$ & 1 & 0.04 & ns & 6.29 & $*$ & 3.13 & 0 & 4.55 & 0 \\
\hline$f \times t$ & 1 & 0.66 & ns & 0.10 & ns & 1.15 & ns & 0.25 & ns \\
\hline $\mathrm{m} \times \mathrm{f} \times \mathrm{t}$ & 1 & 6.22 & $*$ & 0.08 & ns & 9.74 & $* *$ & 0.08 & ns \\
\hline Residuals (MS) & 14 & 8.15 & & 2.51 & & 4.72 & & 2.52 & \\
\hline
\end{tabular}

Only categories with significant effects are presented.

$\mathrm{m}$ : repeated mowing; f: fertilizing; t: trampling; df: degrees of freedom; MS: mean square.

**: $P<0.01, *: P<0.05$, $0: P<0.1$, ns: not significant.

set without the effect of the second was also significant (Figure 3 ). In this case the shared variation was negative. This negative value can appear when there is a strong correlation between the sets (Legendre and Legendre, 1998).

\section{Treatments effects}

ANOVAs were also performed separately for the sunny and shady situation. AWCD and number of culturable bacteria did not show any significant change in relation to the treatments. Nevertheless, four biochemical categories of substrates, three in the sunny (CA, Po, $\mathrm{CH}$ ) and one in the shady (AA) situation, showed significant results (Table 4). The sum of average values of corrected Abs. for each treatment within these four biochemical categories are presented in Figure 4. In the sunny situation, carboxylic acids (Figure 4a) were less used by communities under repeated mowing and there was a significant effect of the triple interaction. For polymers (Figure 4b), samples from plots with trampling treatment showed less use. The interaction between trampling and repeated mowing showed also a significant effect. For carbohydrates (Figure 4c), the triple interaction is significant and the interaction between trampling and repeated mowing was marginally significant. For these three substrates categories, plots with natural cattle activity showed averages values. In the shade, use of amino acids substrates (Figure 4d) was significantly affected by repeated mowing. With this treatment growth was reduced. Shady plots with natural cattle activity showed values similar to abandoned and fertilized plots.

\section{Discussion}

Relationship between microbial communities and light conditions

Despite the differences in plant communities and soil properties, the metabolic potential of the microbial communities in the sunny and in the shady situations were broadly similar (Table 3 and Figure 2). Microbial communities seem to be weakly related to the studied successional gradient of vegetation in terms of functional structure and indeed, for chalk grassland Chabrerie et al. (2003) came to the conclusion of independency. In some cases, microbial community structure (PLFA) and activity $\left(\right.$ Biolog $\left.^{\mathrm{TM}}\right)$ are more influenced by the soil type than by the plants (Buyer et al., 2002).

The only important variation between shady and sunny plots was for AWCD, which was lower in the shady situation. AWCD had very low values after $48 \mathrm{~h}$ and a difference between both situations was always present after 8 days (data not shown). The lag time was then longer than 2 days for both communities and we can interpret the difference as a slower reactivity of the community in the shady situation. This difference 

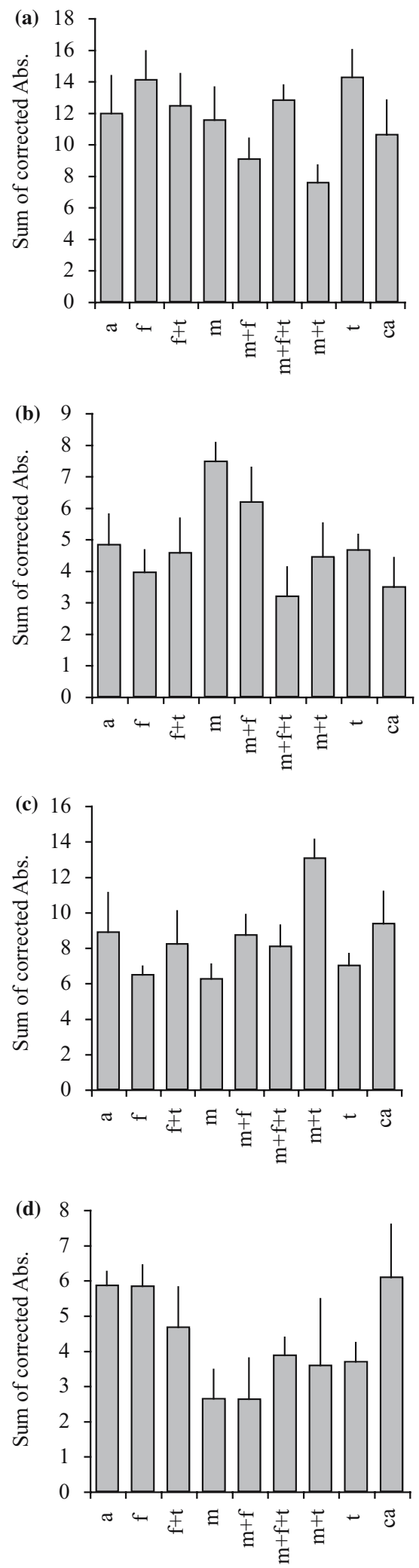

seems to induce only little dissimilarity between profiles after correction of the absorbance.

Carbohydrate substrates were generally slightly more rapidly oxidized in the sunny situation and indeed there was more plant biomass and therefore most likely also more roots exudates, which are known to be rich in carbohydrates (Lynch, 1990). The least used carbohydrate substrates under both conditions, were phosphate sugars. To use these substrates, bacteria must first excrete phosphatase. We can then suppose low phosphatase activity in this soil, whatever the applied treatment. The slightly greater activity on polymers in the shady condition could be explained by the beech litter covering the ground, this litter being completely absent in the sunny situation.

\section{Potential metabolic reactivity at community level after disturbance}

We did not measure the direct effect of the three disturbances but measured their long-term impact by taking samples in spring of the third year of the experiment. Therefore, results must be interpreted as a fingerprint of the potential metabolic reactivity after a disturbance at community level (O'Neill et al., 1986) and not as a direct physiological response.

As shown with partial RDAs, microbial communities seem to react differently to the treatments in sunny and shady situations. The amount of unexplained variation was high in both analyses, like in most ecological studies (Aude and Lawesson, 1998; Borcard et al., 1992). This is usually interpreted as variation caused by unmeasured environmental variables, complex spatial relationships and stochasticity in biological processes (Borcard et al., 1992; Heikkinnen and Birks, 1996).

Treatment effects were more pronounced in the sunny than in the shady situation (Figure 3). In both cases, repeated mowing was the first

Figure 4. Effect of treatments on categories of substrates. Only categories with significant effects in ANOVA (see Table 4) are presented. Sunny situation: Carboxylic acids (a), Polymers (b), Carbohydrates (c), Shady situation: Amino acids (d). f: fertilizing, m: repeated mowing, t: trampling, a: abandoned, ca: normal cattle activity. Error bars indicate standard error. 
factor retained for explaining variation in the Ecoplate $^{\mathrm{TM}}$ data set. Bardgett and Wardle (2003) showed that in the short-term, the quantity of resources supplied to soil can be altered through herbivory and change $\mathrm{C}$ allocation in plants and their root exudation. In a long-term, herbivory influences also the amount of organic material returned to soil through shifts in the net primary production (Milchunas and Lauenroth, 1993). Moreover, herbivory tends to change the functional composition of the plant communities, which in turn also alters the quality of resources supplied to the soil (Bardgett and Wardle, 2003). In our experiment, the vegetation yield was negatively affected by repeated mowing (Kohler, 2004) and this factor was the most important in the sunny situation for explaining plant species differences between plots, followed by trampling. Because soil microbes depend on plant-derived C and are often associated with specific plant species (Ebersberger et al., 2004), repeated mowing can induce important changes in the microbial community. The effect of fertilizing alone on microbial community was not retained as a significant factor in any of our situations, indicating its low impact. Trampling was selected as an important factor in the sunny situation especially when it was coupled with one of the other treatments (Figure 3). Even human trampling in urban forests had an effect on microbial community structure (Malmivaara-Lämsä and Fritze, 2003) but indirectly due to changes in the vegetation and in the litter quality rather than directly through soil compaction. However, in our experiment, treatments seem to have a direct effect on microbial communities because explained variations were always significant after accounting for vegetation or soil effects (Figure 3). The principal difference between light and shade situation was a high proportion of explained variation by the vegetation in the first case, and none in the second. For the soil it was the opposite. The lack of explanation by soil variables in the sunny situation is probably due to the high homogeneity of soil conditions. Similarly, Clegg et al. (2003) showed no significant relationship between PLFA and soil variables such as organic matter, $\mathrm{pH}$, total $\mathrm{C}$ and total $\mathrm{N}$ in grasslands. In our study, only $\mathrm{pH}$ explained part of the variation in the shady situation where soil conditions were slightly less homogeneous than in the sunny situation (Figure 2 and Table 2). This variable is recognized as having an important impact on the microbial communities in grasslands (Grayston et al., 2004). For vegetation, plant species composition coupled with grazing is an important factor governing microbial community structure in upland grasslands (Grayston et al., 2004). This is consistent with our results in the sunny situation. The lack of explanation of vegetation variables in the shady situation is probably due to a low biomass (Table 2) and also lower influence of rhizosphere exudates.

No effect was found either in the number of culturable bacteria or in the AWCD for the different treatments. Apparently, trampling did not reduce the number of aerobic bacteria. Jordan et al. (2003) observed a significant effect of soil compaction on microbial activity by simulating soil compaction by heavy traffic. In an urban forest, Malmivaara-Lämsä and Fritze (2003) measured a decrease of microbial activity due to high human trampling. In our study, the trampling treatment was not as extreme and thus probably not sufficient to have a high significant effect on soil porosity and aeration. Nevertheless, a significant negative effect of trampling on polymers consumption was observed in the sunny situation, which could be attributed to the soil compaction that favors anaerobic micro-sites where enzymatic oxidation of polymers by microorganisms is limited (Gobat et al., 2004). Finally, fertilizing did not affect the number of culturable bacteria, which is in agreement with Bardgett et al. (1999) who found no effect of N-addition on microbial biomass.

\section{Discrimination of microbial communities with Ecoplates $^{\mathrm{TM}}$}

Community level physiological profiles (CLPP), obtained by Biolog ${ }^{\mathrm{TM}}$ microplates, have been used to characterize microbial communities from different plant species and soil types (Garland, 1996; Grayston et al., 2001). CLPP is a measurement of community structure and potential activity of culturable, aerobic and fast growing bacteria (Smalla et al., 1998). However, similar metabolic fingerprints may be reached by structurally different bacterial communities (Miethling et al., 2003). 
Furthermore, caution is required in interpreting the CLPP results since the potential catabolic diversity measured here may not accurately reflect activity under the field conditions. However, despite methodological uncertainty, Ecoplate ${ }^{T M}$ breathprint reflects diversity of carbon-oxidation pathways and therefore functional diversity of soil inhabiting microbial communities.

The 31 Ecoplate $^{\mathrm{TM}}$ substrates have been chosen according to the separation power of environmental samples (Insam, 1997). Biolog GN2 $2^{\text {TM }}$ and Ecoplates ${ }^{\mathrm{TM}}$ revealed similar differences between the CLPP's of assessed water samples, but the use of Ecoplate ${ }^{\mathrm{TM}}$ was recommended because the substrates are ecologically more relevant than those on the Biolog GN2 ${ }^{\text {TM }}$ plate (Choi and Dobbs, 1999). Furthermore, the greatest advantage of Ecoplates ${ }^{\mathrm{TM}}$ is the addition of three replicates of each substrate within a single plate, increasing the likelihood that the CLPP generated is representative for the soil sample assessed (Classen et al., 2003).

In this study, the Ecoplates ${ }^{\mathrm{TM}}$ substrate utilization profiles were able to detect differences for treatments but only partly for shade effect. This result is surprising because treatments applied during two summer periods seem to have been more important to change microbial activities than the presence of an ecological gradient acting since decades. However there are two possible explanations: (i) the microbial communities were indeed physiologically equivalent as suggested results of Chabrerie et al. (2003) who found that microbial activities were independent from vegetation type in terms of functional and genetic structure; (ii) the Ecoplate ${ }^{\mathrm{TM}}$ is not sensitive enough to detect such differences. It is obvious that with this method we obtain only a partial view of the active and fast growing bacterial community (Konopka et al., 1998; Verschuere et al., 1997).

\section{Conclusion}

Aerobic bacterial species with rapid growth were functionally identical along the studied ecological gradient but were sensitive to part of our treatments simulating cattle activity. In other words, the soil and the climatic conditions at the field scale were sufficiently homogenous to drive the functional composition of the whole microbial community, but the cattle may modify by their grazing, trampling and dunging behavior the potential metabolic activity of certain microbial guilds. Therefore, in successive years, cattle activities may change spatially at fine scale and induce changes in the microbial community structure. Thus, the shifting mosaic that has been described for the herbaceous vegetation of pastures (Kohler 2004; Kohler et al., 2004) may also apply for below-ground microbial communities. Further work is required to describe these processes in condition with natural cattle activities.

\section{Acknowledgments}

We acknowledge financial support from the Swiss National Science Foundation (Grant No. 31-64116.00) and the National Centre of Competence in Research (NCCR) "Plant Survival". We are also grateful to Nicolas Küffer and Regula Benz for their help during the fieldwork, to Amélie Fragnière and Noémie Duvanel for help in the lab.

\section{References}

Anderson J M and Ingram J S I 1993 Tropical Soil Biology and Fertility. A Handbook of Methods. 2nd ed. CAB International, Oxford.

Aude E and Lawesson J E 1998 Vegetation in Danish beech forests: The importance of soil, microclimate and management factors, evaluated by variation partitioning. Plant Ecol. 134, 53-65.

Bardgett R D and Wardle D A 2003 Herbivore-mediated linkages between aboveground and belowground communities. Ecology 84, 2258-2268.

Bardgett R D, Wardle D A and Yeates G W 1998 Linking above-ground and below-ground interactions: How plant responses to foliar herbivory influence soil organisms. Soil Biol. Biochem. 30, 1867-1878.

Bardgett R D, Jones A C, Jones D L, Kemmitt S J, Cook R and Hobbs P J 2001 Soil microbial community patterns related to the history and intensity of grazing in sub-montane ecosystems. Soil Biol. Biochem. 33, 1653-1664.

Bardgett R D, Mawdsley J L, Edwards S, Hobbs P J, Rodwell J S and Davies W J 1999 Plant species and nitrogen effects on soil biological properties of temperate upland grasslands. Funct. Ecol. 13, 650-660.

Bokdam J and Gleichman J M 2000 Effects of grazing by freeranging cattle on vegetation dynamics in a continental northwest European heathland. J. Appl. Ecol. 37, 415-431. 
Borcard D, Legendre P and Drapeau P 1992 Partialling out the spatial component of ecological variation. Ecology 73, 10451055.

Breland T A and Hansen S 1996 Nitrogen mineralization and microbial biomass as affected by soil compaction. Soil Biol. Biochem. 28, 655-663.

Buttler A 1992 Permanent plot research in wet meadows and cutting experiment. Vegetatio 103, 113-124.

Buyer J S, Roberts D P and Russek-Cohen E 2002 The rhizosphere effect and microbial community structure. Can. J. Microbiol. 48, 955-964.

Chabrerie O, Laval K, Puget P, Desaire S and Alard D 2003 Relationship between plant and soil microbial communities along a successional gradient in a chalk grassland in northwestern France. Appl. Soil Ecol. 24, 43-56.

Choi K H and Dobbs F C 1999 Comparison of two kind of Biolog microplates (GN and ECO) in their ability to distinguish among aquatic microbial communities. J. Microbiol. Meth. 36, 203-213.

Cingolani A M, Cabido M R, Renison D and Solis V N 2003 Combined effects of environment and grazing on vegetation structure in Argentine granite grasslands. J. Veg. Sci. 14, 223-232.

Classen A T, Boyle S I, Haskins K E, Overby S T and Hart S C 2003 Community-level physiological profiles of bacteria and fungi: plate type and incubation temperature influences on contrasting soils. FEMS Microbiol. Ecol. 44, 319-328.

Clegg C D, Lovell R D L and Hobbs P J 2003 The impact of grassland management regime on the community structure of selected bacterial groups in soils. FEMS Microbiol. Ecol. 43, 263-270.

Cole D N 1995 Experimental trampling of vegetation 1. Relationship between trampling intensity and vegetation response. J. Appl. Ecol. 32, 203-214.

Daget P and Poissonet J 1969 Analyse phytologique des prairies; applications agronomiques. CNRS-CEPE, doc 48, Montpellier.

Dai X 2000 Impact of cattle dung deposition on the distribution pattern of plant species in an alvar limestone grassland. J. Veg. Sci. 11, 715-724.

Deckers J A, Nachtergaele F O and Spaargaren O C (Ed.) 1998 World reference base for soil resources, Introduction. Publishing Company Acco, Leuven.

Donnison L M, Griffith G S, Hedger J, Hobbs P J and Bardgett R D 2000 Management influences on soil microbial communities and their function in botanically diverse haymeadows of northern England and Wales. Soil Biol. Biochem. $32,253-263$.

Ebersberger D, Wermbter N, Niklaus P A and Kandeler E 2004 Effects of long term $\mathrm{CO}_{2}$ enrichment on microbial community structure in calcareous grassland. Plant Soil 264, 313323.

Garland J L 1996 Analytical approaches to the characterisation of samples of microbial communities using patterns of potential C source utilisation. Soil Biol. Biochem. 28, 213221.

Garland J L and Mills A L 1991 Classification and characterization of heterotrophic microbial communities on the basis of patterns of community-level sole-carbon-source utilization. Appl. Environ. Microbiol. 57, 2351-2359.

Gobat J M, Aragno M and Matthey W 2004 The Living Soil: Fundamentals of Soil Science and Soil Biology. Science Publishers, Enfield, New Hampshire.
Gough L, Osenberg C W, Gross K L and Collins S L 2000 Fertilization effects on species density and primary productivity in herbaceous plant communities. Oikos 89,428 439.

Grayston S J, Griffith G S, Mawdsley J L, Campbell C D and Bardgett R D 2001 Accounting for variability in soil microbial communities of temperate upland grassland ecosystems. Soil Biol. Biochem. 33, 533-551.

Grayston S J, Campbell C D, Bardgett R D, Mawdsley J L, Clegg C D, Ritz K, Griffiths B S, Rodwell J S, Edwards S J, Davies W J, Elston D J and Millard P 2004 Assessing shifts in microbial community structure across a range of grasslands of differing management intensity using CLPP, PLFA and community DNA techniques. Appl. Soil Ecol. 25, 6384.

Griffiths R I, Whiteley A S, O'Donnell A G and Bailey M J 2003 Influence of depth and sampling time on bacterial community structure in an upland grassland soil. FEMS Microbiol. Ecol. 43, 35-43.

Guethery F S and Bingham R L 1996 A theoretical basis for study and management of trampling cattle. J. Range. Manage. 49, 264-269.

Guitian R and Bardgett R D 2000 Plant and soil microbial responses to defoliation in temperate semi-natural grassland. Plant Soil 220, 271-277.

Harrison K A and Bardgett R D 2004 Browsing by red deer negatively impacts on soil nitrogen availability in regenerating native forest. Soil Biol. Biochem. 36, 115-126.

Heikinnen R K and Birks H J B 1996 Spatial and environmental components of variation in the distribution patterns of subartic plant species at Kevo, N Finland - a case study at the meso-scale level. Ecography 19, 341-351.

Holland E A and Detling J K 1990 Plant-response to herbivory and belowground nitrogen cycling. Ecology 71, 1040-1049.

Insam H 1997 A new set of substrates proposed for community characterization in environmental samples. In Microbial Communities. Eds. H Insam and A Rangger. pp. 259-260. Springer-Verlag.

Jordan D, Ponder F and Hubbard V C 2003 Effects of soil compaction, forest leaf litter and nitrogen fertilizer on two oak species and microbial activity. Appl. Soil Ecol. 23, 33-41.

Kaufmann K, Christophersen M, Buttler A, Harms H and Höhener P 2004 Microbial community response to petroleum hydrocarbon contamination in the unsaturated zone at the experimental field site Værløse, Denmark. FEMS Microbiol. Ecol. 48, 387-399.

Kohler F, 2004 Influence of grazing, dunging and trampling on short-term dynamics of grasslands in mountain wooded pasture. PhD Thesis, University of Neuchâtel, Neuchâtel, $184 \mathrm{pp}$.

Kohler F, Gillet F, Gobat J M and Buttler A 2004 Seasonal vegetation changes in mountain pastures due to simulated effects of cattle grazing. J. Veg. Sci. 15, 143-150.

Konopka A, Olivier L and Turco R F Jr 1998 The use of carbon substrate utilization patterns in environmental and ecological microbiology. Microbial. Ecol. 35, 103-115.

Larkin R P 2003 Characterization of soil microbial communities under different potato cropping systems by microbial population dynamics, substrate utilization, and fatty acid profiles. Soil Biol. Biochem. 35, 1451-1466.

Legendre P and Gallagher E D 2001 Ecologically meaningful transformations for ordination of species data. Oecologia 129, 271-280. 
Legendre P and Legendre L 1998 Numerical ecology. 2nd English ed. Elsevier Science, BV, Amsterdam.

Lynch J M 1990 The Rhizosphere. John Wiley and Sons Ltd, Chichester.

Malmivaara-Lämsä M and Fritze H 2003 Effects of wear and above ground forest site type characteristics on the soil microbial community structure in an urban setting. Plant Soil 256, 187-203.

Malo J E and Suarez F 1995 Establishment of pasture species on cattle dung - the role of endozoochorous seeds. J. Veg Sci. 6, 169-174.

Martinez L J and Zinck J A 2004 Temporal variation of soil compaction and deterioration of soil quality in pasture areas of Colombian Amazonia. Soil Till. Res. 75, 3-17.

Miethling R, Ahrends K and Tebbe C C 2003 Structural differences in the rhizosphere communities of legumes are not equally reflected in community-level physiological profiles. Soil Biol. Biochem. 35, 1405-1410.

Milchunas D G and Lauenroth W K 1993 Quantitative effects of grazing on vegetation and soils over a global range of environments. Ecol. Monogr. 63, 327-366.

Økland R H and Eilertsen O 1994 Canonical correspondenceanalysis with variation partitioning - some comments and an application. J. Veg. Sci. 5, 117-126.

Olff H, Vera F W M, Bokdam J, Bakker E S, Gleichman J M, de Maeyer K and Smit R 1999 Shifting mosaics in grazed woodlands driven by the alternation of plant facilitation and competition. Plant Biol. 1, 127-137.

O'Neill R V, DeAngelis D L, Waide J B and Allen T H F 1986 A Hierarchical Concept of Ecosystems. Princeton University Press, Princeton.

R Development Core Team 2004 R: A language and environment for statistical computing. R Foundation for Statistical Computing, Vienna, Austria. ISBN 3-900051-00-3, URL http://www.R-project.org.

Ruess R W and McNaughton S J 1987 Grazing and the dynamics and energy regulated microbial processes in the Serengeti grassland. Oikos 49, 101-110.

Ryser J-P, Walther U and Flisch R 2001 Données de base pour la fumure des grandes cultures et des herbages. Revue Suisse d'Agriculture 33, 1-80.
Schlaepfer M, Zoller H and Koerner C 1998 Influences of mowing and grazing on plant species composition in calcareous grassland. Bot. Helv. 108, 57-67.

Smalla K, Wachtendorf U, Heuer H, Liu W T and Forney L 1998 Analysis of BIOLOG GN substrate utilization patterns by microbial communities. Appl. Environ. Microbiol. 64, $1220-1225$.

ter Braak C J F and Smilauer P 2002 CANOCO Reference manual and CanoDraw for Windows User's guide: Software for canonical community ordination (version 4.5). Microcomputer Power, Ithaca.

Tracy B F and Frank D A 1998 Herbivore influence on soil microbial biomass and nitrogen mineralization in a northern grassland ecosystem: Yellowstone National Park. Oecologia 114, 556-562.

Tutin T G, Heywood V H, Burges N A, Valentine D H, Walters S M and Webb D A 1964-1980 Flora europaea. Band 1-5. Cambridge University Press, Cambridge.

Verschuere L, Fievez V, Van Vooren L and Verstraete W 1997 The contribution of individual populations to the Biolog pattern of model microbial communities. FEMS Microb. Ecol. 24, 353-362.

Wardle D A, Bonner K I, Barker G M, Yeates G W, Nicholson K S, Bardgett R D, Watson R N and Ghani A 1999 Plant removals in perennial grassland: Vegetation dynamics, decomposers, soil biodiversity, and ecosystem properties. Ecol. Monogr. 69, 535-568.

Whalley W R, Dumitru E and Dexter A R 1995 Biological effects of soil compaction. Soil Till. Res. 35, 53-68.

Williams B L, Grayston S J and Reid E J 2000 Influence of synthetic sheep urine on the microbial biomass, activity and community structure in two pastures in the Scottish uplands. Plant Soil 225, 175-185.

Yeates G W, Bardgett R D, Cook R, Hobbs P J, Bowling P J and Potter J F 1997 Faunal and microbial diversity in three Welsh grassland soils under conventional and organic management regimes. J. Appl. Ecol. 34, 453-470.

Zak J C, Willig M R, Moorhead D L and Wildman H G 1994 Functional diversity of microbial communities: A quantitative approach. Soil Biol. Biochem. 26, 1101-1108.

Section editor: C. Neill 